IZA DP No. 5435

Reservation Wages and Starting Wages

Hans van Ophem

Joop Hartog

Peter Berkhout

January 2011 


\title{
Reservation Wages and Starting Wages
}

\author{
Hans van Ophem \\ University of Amsterdam
}

\author{
Joop Hartog \\ University of Amsterdam \\ and IZA
}

Peter Berkhout

EIB Amsterdam

\section{Discussion Paper No. 5435 \\ January 2011}

IZA

P.O. Box 7240

53072 Bonn

Germany

Phone: +49-228-3894-0

Fax: +49-228-3894-180

E-mail: iza@iza.org

Any opinions expressed here are those of the author(s) and not those of IZA. Research published in this series may include views on policy, but the institute itself takes no institutional policy positions.

The Institute for the Study of Labor (IZA) in Bonn is a local and virtual international research center and a place of communication between science, politics and business. IZA is an independent nonprofit organization supported by Deutsche Post Foundation. The center is associated with the University of Bonn and offers a stimulating research environment through its international network, workshops and conferences, data service, project support, research visits and doctoral program. IZA engages in (i) original and internationally competitive research in all fields of labor economics, (ii) development of policy concepts, and (iii) dissemination of research results and concepts to the interested public.

IZA Discussion Papers often represent preliminary work and are circulated to encourage discussion. Citation of such a paper should account for its provisional character. A revised version may be available directly from the author. 
IZA Discussion Paper No. 5435

January 2011

\section{ABSTRACT}

\section{Reservation Wages and Starting Wages ${ }^{*}$}

We analyse a unique data set that combines reservation wage and actually paid wage for a large sample of Dutch recent higher education graduates. On average, accepted wages are almost $8 \%$ higher than reservation wages, but there is no fixed proportionality. We find that the difference between reservation wage and accepted wage is virtually random, as search theory predicts. We also find that most information contained in the accepted wage is included in the reservation wage, as one would predict if individuals are well informed about the wage structure that characterizes their labour market.

JEL Classification: $\quad J 31, \mathrm{~J} 69$

Keywords: reservation wages, starting wages, job search

Corresponding author:

Hans van Ophem

Department of Quantitative Economics

University of Amsterdam

Roetersstraat 11

1018 WB Amsterdam

The Netherlands

E-mail: j.c.m.vanophem@uva.nl

\footnotetext{
* All ML-routines used in this paper are either performed by using standard routines from Stata or are carried out using $\mathrm{R}$ (free software, for information see http://www.r-project.org/). All computer programs are available on request.
} 


\section{Introduction}

The reservation wage for accepting a job is a key concept but it is seldom measured directly. We will analyse data for recent graduates and ask how well individuals perceive the market wage structure as reflected in market wages. The reservation wage plays an important role in job search theory (cf. Lippman and McCall (1976) or Eckstein and van den Berg (2007) for a survey). In the first instance, this theory was proposed to describe the job finding process of the unemployed (e.g Kiefer and Neumann (1979), Jones (1988)). Later, it was extended to job-to-job mobility (e.g Burdett (1978)) and the transition from school to work (e.g. Wolpin (1987) and Eckstein and Wolpin (1995)). Irrespective of the situation to which the job search theory is applied, the basic structure remains the same. In the simplest stationary setup, a group of homogenous individuals is searching for a job. They employ all kinds of search activities in order to receive job offers, and it is assumed that in each period these arrive with constant probability $\delta$. The job offer made by the potential employer is characterized by the wage (w) and comes randomly from a distribution $F(w)$. If we denote the discount factor by $\rho$, the optimal strategy of an individual is to accept a job offer if it exceeds the reservation wage $\left(w^{r}\right) .^{3}$ The reservation wage solves the following equation:

$$
w^{r}=b+\frac{\delta}{\rho} \int_{w^{r}}^{\infty}\left(w-w^{r}\right) d F(w)=b+\frac{\delta}{\rho} P\left(w>w^{r}\right) E\left(w-w^{r} \mid w>w^{r}\right)
$$

where $b$ is the monetary value of being in the present state. The basic model can be easily illustrated by writing the right-hand side of (1) as $b+\frac{\delta}{\rho} g\left(w^{r}\right)$, where $g\left(w^{r}\right)$ measures the expected value of the gap between market wage and reservation wage. The gap depends on the probability of obtaining a wage offer above the reservation wage and the conditional expectation of the difference between market wage and reservation wage. It is straightforward to deduce that both the probability and the conditional expectation are declining in the reservation wage and hence, $g\left(w^{r}\right)$ is declining in the reservation wage. The equilibrium value of the reservation wage depends on the labour supplier's opportunity cost $b$ of accepting the wage offer, on discount rate $\rho$, wage offer arrival rate $\delta$ and on the parameters of the

3 For a proof see Lippman and McCall (1976). 
wage offer distribution, as illustrated in Figure 1. Anything that shifts up the right hand side of equation (1) will shift up the equilibrium wage rate and hence, the accepted (conditional) market wage, but less so than the shift in the right hand side. Thus an increase in opportunity cost $b$ and in the mean of the wage offer distribution will increase the reservation wage. The latter prediction implies that a variable that affects the mean of the wage offer distribution will affect the reservation in the same direction. An increase in opportunity cost $b$ will increase the reservation wage and hence the conditional expectation of the market wage rate. However, it's hard to predict relative magnitudes on (conditional) wages, as this will depend on specific and as yet unknown parameter values (wage offer arrival rate, discount rate, functional form of the wage offer distribution) ${ }^{4}$.

Figure 1: The equilibrium reservation wage

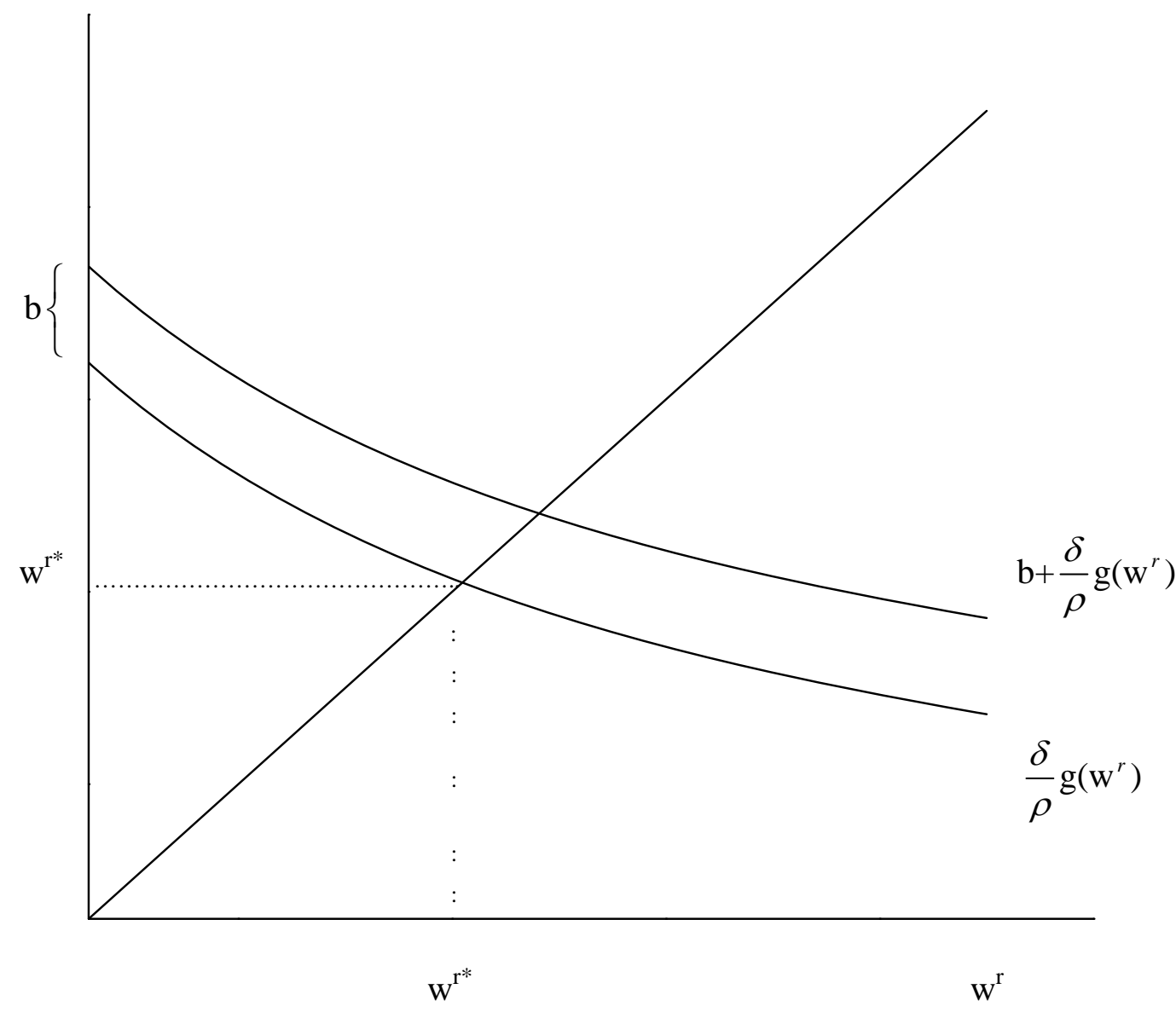

4 Lancaster and Chesher (1983) derive, for model (1) that the elasticity of the reservation wage for unemployment benefit and for the wage offer arrival rate are both smaller than 1 , and estimate values between .10 and .15 for a UK sample of unemployed in 1973. 
Clearly, the assumptions of this model are quite restrictive and many generalizations can be proposed. An important one is to allow for changes in the parameters of the model over time (nonstationarity). As such this does not change the optimal search strategy but the reservation wage is no longer constant in time but dependent on the duration of search: declining opportunity cost or updates of parameters of the wage offer distribution can easily be traced in Figure 1. In the literature, the distribution of the wage offers has been made to depend on worker characteristics like work experience and unemployment duration (Wolpin (1987) and Burdett and Vishwanath (1988)). Also the relation between the level of search activity and the job arrival rate has been investigated extensively (e.g. Benhabib and Bull (1983, Pissarides (1984), Balu and Robins (1990) and Bloemen (2005)).

Most empirical contributions to the search theory only seek to estimate a few structural parameters, such as the discount rate, the job offer arrival rate and parameters of the job offer distribution. Much work concentrated on analysis of the duration of unemployment, in which the reservation wage only plays an implicit role and there is no need to actually observe it (e.g. Kiefer and Neumann (1979) or van den Berg and Ridder (1998)). Similar research on the transition from school to work can be found in Wolpin (1987), Eckstein and Wolpin (1995, 1999), Bowlus et al (2001) and van der Klaauw and van Vuuren (2009). This does not mean that in this type of research no inferences can be made. Indeed, some researchers investigate reservation wages on the basis of its implicit definition in a search model (cf. Kiefer and Neumann (1979), Wolpin (1987), Eckstein and Wolpin (1995), Bowlus et al (2001), Gørgens (2002) and van der Klaauw and van Vuuren (2010)) and others use the stochastic frontier methodology (Hofler and Murphy (1994), Webb et al (2003) and Watson and Webb (2008)).

In the SEO/Elsevier data that will be used in this paper, we are in the special position that reservation wages are actually reported. One of the first empirical investigations using actually reported information on the reservation wage can be found in Kasper (1976). Since then a limited number of similar papers has been published. One of the most influential papers is Lancaster and Chesher (1983). They conclude, among other things, that "people can answer questions suggested by optimal search theory and that their answers are both numerically consistent with that theory" (Lancaster and Chesher, 1983, p. 1674). More recent empirical research on actual reservation wages is reported in Jones (1988), Bloemen and Stancanelli (2001) and Blackaby et al (2007). Going from the analysis of the unemployment to the 
analysis of young graduates does not require large changes in the models that are employed. The magnitude of the parameters like the arrival rate of job offers or the characteristics of the job offer distribution, can be markedly different but the general setup remains the same.

Availability of observations on individual reservation wages opens up several interesting opportunities. Observing a meaningful structure of reservation wages can increase support for the theory (or, in the converse case, raise doubts), it can be useful for policy purposes (like setting an optimal unemployment benefit level) and it can test implications of the theory. We will focus mostly on the quality of the information that individuals use. Search theory assumes that individuals set their reservation wage in response to their perception of the market in which they search for a job. Their reservation wage will reflect their perception of the wage offer distribution. Thus we expect that reservation wage and market wage will move in tandem: variables that affect the market wage should affect the reservation wage in the same direction and presumably by comparable magnitudes. Systematic deviations between the two effects suggest that individuals do not have adequate information on the wage structure they are facing. Search theory also implies that the difference between an individual's accepted wage and the individual's reservation wage is random: the reservation wage reflects perceived market conditions and the accepted wage is just a random draw from the wage offer distribution, conditional on surpassing the reservation wage.

The relation between the reservation wage and the market wage has been disregarded in the empirical literature. In our data set we have individually reported reservation wages for the present job and the starting wage in that job. As discussed above, in general we can state that the reservation wage depends on the job arrival rate, the discount rate, the utility of the present position and the distribution of the wage offers. If we assume that this distribution is characterized by $\mu_{\mathrm{w}}$ and $\sigma_{\mathrm{w}}{ }^{2}$ and that the relation of logarithm of $\mathrm{w}^{\mathrm{r}}$ and the underlying factors can be approximated by a linear equation we can write:

$$
\log \left(w^{r}\right)=\theta_{0}+\theta_{1} b+\theta_{2} \delta+\theta_{3} \rho+\theta_{4} \mu+\theta_{5} \sigma_{w}^{2}+\xi
$$

Under the same assumption it is straightforward to specify the starting wage, i.e. the job offer accepted by the individual and therefore exceeding the reservation wage, as:

$$
\log \left(w^{r}\right)=\eta_{0}+\eta_{1} \mu+\varepsilon
$$


where the variance of the error terms is likely to bear some relation with $\sigma_{\mathrm{w}}{ }^{2}$. Not only does the same factor play an important role in both specifications, but also if we account for the fact that $\mu$ is not observed and therefore has to approximated, it is quite likely that the error terms will display a positive correlation. In spite of this correlation, eqs. (2) and (3) can be estimated with OLS as long as we are willing to assume that we actually observe both wages. Unfortunately, this is not obvious from the reservation and starting wages we observe. Reservation wage and starting wage are asked in the same questionnaire, at the same time (asking reservation wage upon entering the market would obviously have been preferable). In more than $30 \%$ of the observations the reservation and starting wage are equal. ${ }^{5}$ This seems an excessive figure and one can raise the question whether a considerable number of the respondents had difficulty ${ }^{6}$ to indicate what their reservation wage is. They appear to have found a simple solution by plugging in the answer to the previous question: the starting wage. As a result we have to adapt our empirical model to accommodate this problem.

If we take it one step further, the reporting of equal reservation and starting wage might only be the top of the iceberg. In might well be that the respondents put down an estimate like the following of their reservation wage: ${ }^{7}$

$$
w^{r}=\omega w^{s} \text { or } \log \left(w^{r}\right)=\log (\omega)+\log \left(w^{s}\right) \quad \text { where } 0<\omega \leq 1
$$

Individuals do not have a clue about what a reservation wage is ${ }^{8}$, but understand that it should be lower than the offered wage and decide to report some proportion. Some use 1, others use $\omega$. It is simple to test (4) against (2). If (4) holds, b, $\delta$ and $\rho$ do not play a role in the determination of the reservation wage, the coefficient of $\mu$ is one and the correlation between the error terms in (2) and (3) will be very high: 1 in fact. Unfortunately, this is only theory. In practice we do not observe the actual determinants of the reservation wage as postulated in (2). Still, estimation results based on proxies of these factors will give us information on the

5 Note that as such this is not contradicting job search theory: the reservation wage never exceeds the actual offered wage.

6 An alternative explanation is unwillingness. We expect that putting down the reservation wage is less sensitive than stating actual or starting wage.

7 Note that this specification shows a remarkable resemblance with the stochastic frontier approach to identify the reservation wage (Hofler and Murphy, 1994, p. 964).

8 Of course, the phrasing of the reservation wage question has been done very carefully. Nonetheless, if people do not think in terms of the theoretical concepts of search theory, they are bound to give careless, sloppy or easy answers. 
reliability of the reported reservation wages.

\section{Empirical model}

In the first instance the analysis of reservation and starting wages seems to be straightforward.

Denote the reservation and starting wage by $w_{i}^{r}$ and $w_{i}^{s}$. We will employ the usual logarithmic specification to relate these wages to the explanatory variables. Since we observe both wages we can simply specify

$\log \left(w_{i}^{r}\right)=X_{r i}{ }^{\prime} \beta_{r}+\varepsilon_{r i}$

$\log \left(w_{i}^{s}\right)=X_{s i}{ }^{\prime} \beta_{s}+\varepsilon_{s i}$

and estimate with OLS. If we allow for a possible correlation between the error terms, we can apply SURE or MLE under the assumption of a bivariate normal distribution. This will render more efficient estimates. As we discussed before, there is a problem however. There appear to be an excess number of observations with equality between reservation and starting wage. For $29.3 \%$ of the observations this holds, whereas from theory only a marginal proportion is expected. Ignoring this feature might result in biased estimates and therefore we decided to take account of the peculiarity of the data. Let's distinguish two categories of observations:

I. The observations with starting wage equal to the reservation wage: $w_{i}^{r}=w_{i}^{s}$

II The observations with starting wage unequal to the reservation wage: $w_{i}^{r}<w_{i}^{s}$

In the first case we are not sure that we can trust the observed reservation wage and we will simply ignore it; we will only impose that $w_{i}^{r}<w_{i}^{s}$. Clearly, we can also not be sure that the process that governs careless reporting of equality between reservation and starting wage is independent of the formation of these wages. Let's model the possibility that individuals will quote the reservation wage to be equal to the offered wage in the usual way:

$I_{i}^{*}=Z_{i}^{\prime} \gamma+\zeta_{i}$

$I_{i}=0$ if $I_{i}^{*} \leq 0$ for observations with $w_{i}^{r}=w_{i}^{s}$

$I_{i}=1$ if $I_{i}^{*}>0$ for observations with $w_{i}^{r}<w_{i}^{s}$ 
For observational categories I and II we get the following likelihood contributions:

$$
\begin{aligned}
& P_{I i}=P\left(I_{i}^{*} \leq 0 ; \log \left(w_{i}^{r}\right) \leq \log \left(w_{i}^{s}\right) ; \log \left(w_{i}^{s}\right)=\tilde{w}_{i}^{s}\right) \\
& P_{I I i}=P\left(I_{i}^{*}>0 ; \log \left(w_{i}^{r}\right) \leq \tilde{w}_{i}^{r} ; \log \left(w_{i}^{s}\right)=\tilde{w}_{i}^{s}\right)
\end{aligned}
$$

Since we already specified the logwages (cf. (1), we have a complete model apart from the assumptions on the distribution of the error terms:

$$
\left(\begin{array}{c}
\zeta_{i} \\
\varepsilon_{r i} \\
\varepsilon_{s i}
\end{array}\right) \sim N\left(\left(\begin{array}{l}
0 \\
0 \\
0
\end{array}\right),\left(\begin{array}{ccc}
1 & \sigma_{1 r} & \sigma_{1 s} \\
\sigma_{1 r} & \sigma_{r}^{2} & \sigma_{s} \\
\sigma_{1 s} & \sigma_{r s} & \sigma_{s}^{2}
\end{array}\right)\right)
$$

Specification (4) can be rewritten as:

$\log \left(w_{i}^{r}\right)=\log \left(w_{i}^{s}\right)+\bar{\omega}+\left(\omega_{i}-\bar{\omega}\right)=X_{s i}{ }^{\prime} \beta_{s}+\bar{\omega}+\left(\varepsilon_{s i}+\left(\omega_{i}-\bar{\omega}\right)\right)$

where $\bar{\omega}$ is the expectation of $\omega_{i}$. This corresponds to the previous model if we impose the restriction $\beta_{s}=\beta_{r}$ apart from the constant. Alternatively, we can add $\log \left(w_{i}^{s}\right)$ to the specification of the reservation wage and $\beta_{r}$, apart from the constant, should equal 0 .

\section{Data}

We use data from the Elsevier/SEO survey, held among recent graduates from Dutch tertiary education. A new cohort of graduates has been interviewed every year since 1996, with focus on outcomes in the first 20 months in the labour market. Dutch tertiary education is basically divided into two levels: higher vocational education (in Dutch abbreviated as HBO) and university education (WO). HBO-education prepares students for specific (categories of) professions. It is taught at about 60 special institutes evenly spread over the Netherlands. On average, 50,000 students graduate each year from HBO. WO-education is considered to be of a somewhat higher intellectual level and has a more general academic character; it also requires a higher level of secondary education for direct admission. It is taught at 14 
universities. Approximately 23,000 students graduate every year. At HBO-level students can choose between 250 different courses of study, while at WO-level they may choose between 260 different specializations. The survey is restricted to the years 2005, 2006, 2007 and 2008 because only for these years a reservation wage is available. We pool these four cohorts, with a time dummy to distinguish them. Earnings are defined as log net hourly wages at the time the respondent started working in his present job. Salaries are self-reported and may contain the associated noise. The net hourly starting wage is calculated from the answer to the following question in the survey: "What was the net monthly wage when you started in your present job? Also indicate how many hours you had to work according to the labour contract." The net hourly reservation wage is calculated from the answer to the following question: "Suppose that during the negotiations for your present job, the employer would have offered you a considerably lower wage. What net monthly wage would have been just acceptable to you (assuming that the number of working hours remains the same)?" Note that we do not actually use the real wages when entering the labour market, but the starting wage at the present employer, very early in the career of the respondents. As Table 2 below indicates, for $56.5 \%$ of respondents this is their first job.

Table 1: Descriptive statistics of the hourly reservation and net hourly starting wages

\begin{tabular}{lrrrrr}
\hline & mean & sd & min & max & $\mathrm{N}$ \\
\hline $\log$ reservation wage $\left(\log \mathrm{w}^{\mathrm{r}}\right)$ & 2.541 & 0.209 & 1.778 & 3.377 & 10575 \\
$\log$ starting wage $\left(\log \mathrm{w}^{\mathrm{s}}\right)$ & 2.595 & 0.212 & 1.839 & 3.389 & 10575 \\
$\log \mathrm{w}^{\mathrm{s}}-\log \mathrm{w}^{\mathrm{r}}$ & 0.054 & 0.054 & 0 & 0.223 & 10575 \\
$\log \mathrm{w}^{\mathrm{r}} \mid \mathrm{w}^{\mathrm{r}}<\mathrm{w}^{\mathrm{s}}$ & 2.541 & 0.198 & 1.779 & 3.377 & 7472 \\
$\log \mathrm{w}^{\mathrm{s}} \mid \mathrm{w}^{\mathrm{r}}<\mathrm{w}^{\mathrm{s}}$ & 2.617 & 0.199 & 1.839 & 3.389 & 7472 \\
$\log \mathrm{w}^{\mathrm{s}}-\log \mathrm{w}^{\mathrm{r}} \mid \mathrm{w}^{\mathrm{r}}<\mathrm{w}^{\mathrm{s}}$ & 0.076 & 0.049 & 0.000 & 0.223 & 7472 \\
\hline
\end{tabular}

For our empirical purposes, we excluded all respondents who are self-employed and all those for whom information on starting and reservation wages and data on important control variables are unavailable. On top of that we deleted the observations for which the reported reservation wage exceeded the starting wage (5.4\% of the sample). In some cases we repaired the problem of the unavailability of a control variable by putting the value at 0 and 
adding a dummy variable. The resulting number of observations is $10575 .^{9}$ Of these observations, 1469 come from the 2005-questionnaire, 3382 from the 2006-questionnaire, 2992 come form the 2007-questionnaire and 2732 come from the 2008 questionnaire.

Table 1 contains information on the logarithm of the net hourly reservation and starting wages and Figures 2, 3 and 4 give the corresponding histograms. If we consider the complete sample, the average hourly starting wage is about $€ 13.40$ and the reservation wage is about $5.4 \%$ lower. This is a modest figure, indicating that recent graduates have a good idea what they are worth on the labour market. The number of observations with equal reservation and starting wages is quite large: $29.3 \%$ of the respondents fall in this category. Apparently some respondents have trouble with answering the reservation wage question. As a result we decided to adapt our empirical model to allow for these potentially incorrectly reported reservation wages (cf. section 2). If we concentrate on the sample for which the reservation wage is lower then the starting wage, 7472 observations, we find that the difference between the starting wage and the reservation wage is $7.6 \%$. The correlation between both wages is extremely high: 0.967 (complete sample) and 0.969 (reduced sample). This might again be an indication that the respondents have a hard time to understand the question related to the reservation wage or it might be that individuals have a very good idea what their wage should be.

At first glance the normal distribution appears to be a convenient distribution to use for both the log net hourly starting and reservation wage. The Bera-Jarque normality test, however, reveals that normality has to be rejected in both cases: we find test statistics 228.85 (starting wage) and 447.51 (reservation wage, reduced sample), which are both considerably larger than the chi-square (2) critical values at 1\%. The histogram in Figure 4 shows that indeed the difference between the starting and reservation wage is small. Few observations are encountered with a difference of more than 20\% (346 observations or 3.3\%). But the graph also clearly indicates that the gap is not a constant fraction of the starting wage. While indeed some anchoring of the reservation wage on actual starting wage should be expected, there is no simple proportionality between reservation wage and starting wage.

9 The sample we start with contains 29152 observations. For more than $40 \%$ of these observations we do not observe both the reservation and starting wage. 5.8\% of the observations have a reservation wage larger than the starting wage. After deletion of variables with incorrect or missing information on the wages we are left with 14134 observations. After we delete the observations with incorrect or missing information on important explanatory variables we have 10575 observations to work with. 
Figure 2: Histogram of the logarithm of the net hourly starting wages

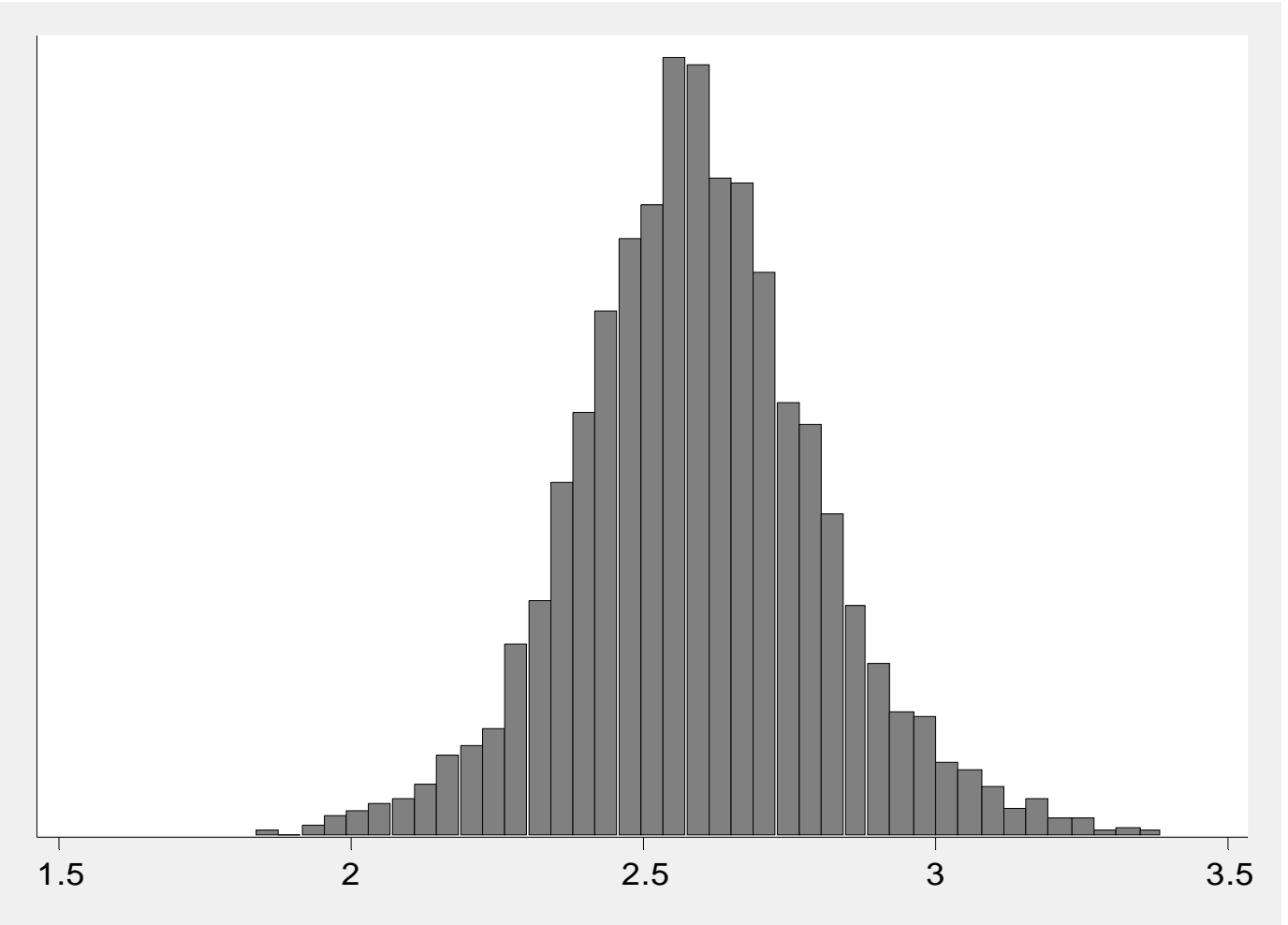

Figure 3: Histogram of logarithm of the net hourly reservation wages

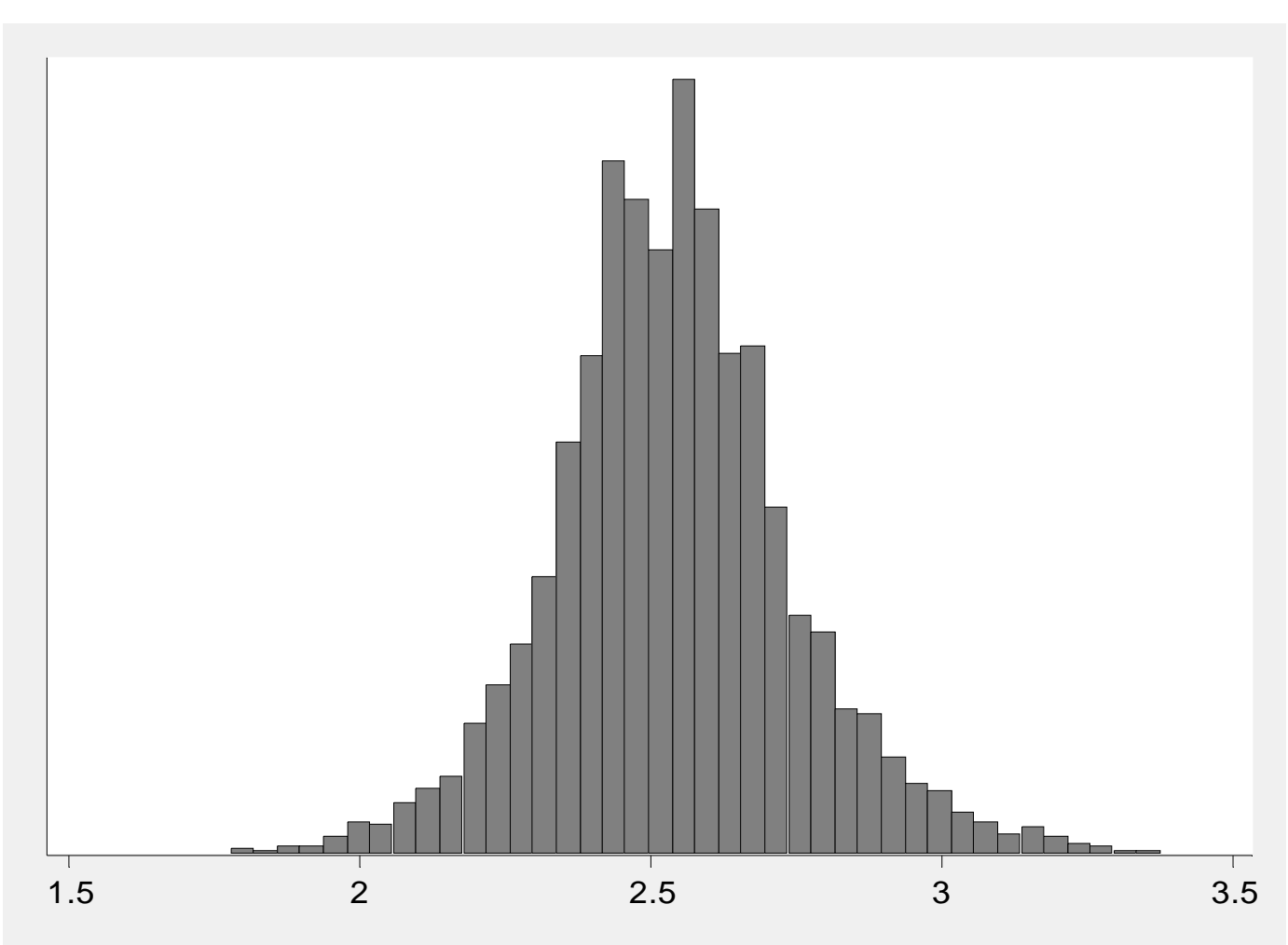




\section{Figure 4: Histogram of the difference between logs of the net hourly starting and reservation wages}

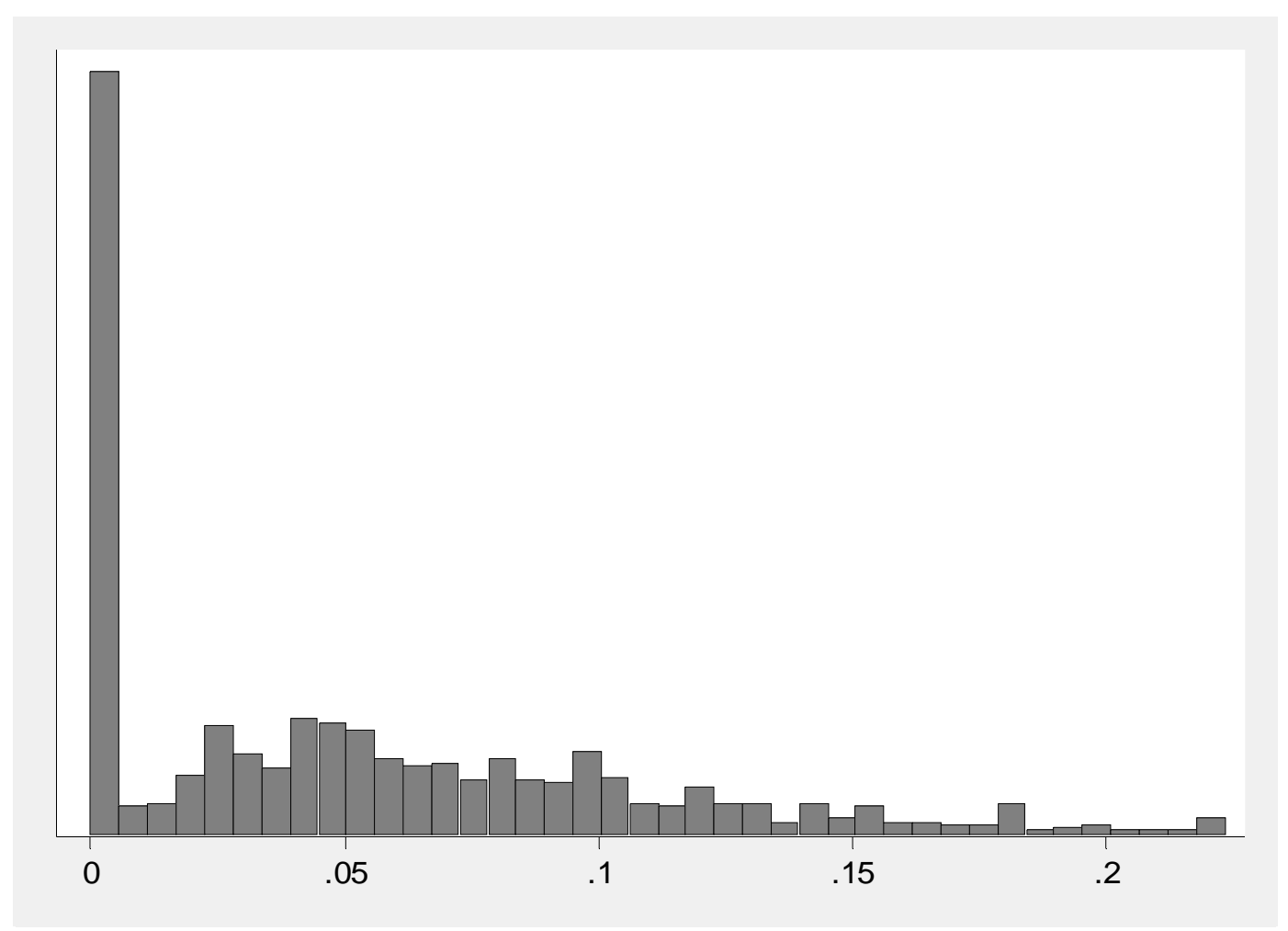

The explanatory variables can be arranged in five categories: characteristics of the individual, characteristics of the education graduated from, variables relating to labour market experience, variables relating to job search and characteristics of the job. A list of variable definitions is given in Appendix A. Only a few variables need discussion here. "Fast graduate” is a dummy variable equal to 1 if the student graduates in less than the nominal duration (usually 4 years), "Slow graduate" is a dummy variable equal to 1 if the actual duration of university or higher vocational education is longer than 6 years. Work experience is divided in experience before and after graduation ("pre" and "post") and the respondent may state whether this experience was relevant or not for the present job.

Descriptive statistics can be found in Table 2. We also indicated the proportion of the missings for each of the variables. For some explanatory variables, the number of applications, the number of interviews and especially the number of job perks, the proportion is large. Deleting these variables altogether did not strike us as a good idea and indeed the estimation results show that these variables have a significant impact. Note that there might be an endogeneity issue as well. The search related variables but also the number of job perks and the absolute deviation in actual and desired working hours might be related tot the error 
terms in the model simply because these variables involve a choice. Since we believe that these explanatory variables are important ${ }^{10}$, it is no option to simply delete them from the specification. For linear regression we have the option to use IV. We experimented with this

Table 2: Descriptive statistics of the explanatory variables.

\begin{tabular}{|c|c|c|c|c|c|}
\hline & mean & sd & $\min$ & $\max$ & $\begin{array}{c}\text { prop. } \\
\text { unknown }\end{array}$ \\
\hline Male & 0.470 & 0.499 & 0 & 1 & 0.0 \\
\hline physically disabled & 0.093 & 0.291 & 0 & 1 & 0.0 \\
\hline Age & 27.231 & 3.569 & 22 & 63 & 0.0 \\
\hline non Dutch & 0.051 & 0.220 & 0 & 1 & 0.0 \\
\hline education mother $a$ & 2.867 & 1.048 & 1 & 5 & 1.1 \\
\hline Partner & 0.511 & 0.499 & 0 & 1 & 0.0 \\
\hline partner wo educated & 0.160 & 0.367 & 0 & 1 & 0.0 \\
\hline partner hbo educated & 0.148 & 0.355 & 0 & 1 & 0.0 \\
\hline partner parttimer & 0.078 & 0.269 & 0 & 1 & 0.0 \\
\hline partner fulltimer & 0.394 & 0.489 & 0 & 1 & 0.0 \\
\hline partner parttimer $\mathrm{x}$ higher educated & 0.030 & 0.170 & 0 & 1 & 0.0 \\
\hline partner fulltimer $\mathrm{x}$ higher educated & 0.267 & 0.442 & 0 & 1 & 0.0 \\
\hline Child & 0.051 & 0.219 & 0 & 1 & 0.0 \\
\hline living with parents $a$ & 0.134 & 0.340 & 0 & 1 & 0.8 \\
\hline north & 0.073 & 0.260 & 0 & 1 & 0.0 \\
\hline West & 0.543 & 0.498 & 0 & 1 & 0.0 \\
\hline South & 0.204 & 0.402 & 0 & 1 & 0.0 \\
\hline logdebt $a$ & 0.958 & 1.357 & -6.908 & 4.382 & 0.8 \\
\hline no debt a & 0.497 & 0.500 & 0 & 1 & 0.8 \\
\hline academic degree & 0.544 & 0.498 & 0 & 1 & 0.0 \\
\hline average exam grade & 7.204 & 0.535 & 6 & 10 & 0.0 \\
\hline duration of education short $a$ & 0.485 & 0.499 & 0 & 1 & 2.0 \\
\hline duration of education long $a$ & 0.246 & 0.431 & 0 & 1 & 2.9 \\
\hline studied abroad & 0.239 & 0.427 & 0 & 1 & 0.0 \\
\hline membership of a student association & 0.521 & 0.500 & 0 & 1 & 0.0 \\
\hline
\end{tabular}

10 And this is confirmed by the estimation results. 
Table 2 continued

\begin{tabular}{lrrrrr}
\hline & mean & sd & min & max & $\begin{array}{c}\text { prop. } \\
\text { Unknown }\end{array}$ \\
\hline pre-experience & 2.760 & 8.214 & 0 & 55 & 0.0 \\
not relevant pre-experience & 0.288 & 0.453 & 0 & 1 & 0.0 \\
pre-experience due to internship & 0.728 & 0.449 & 0 & 1 & 0.0 \\
pre-experience typical student job & 0.473 & 0.499 & 0 & 1 & 0.0 \\
relevant pre-experience & 0.330 & 0.470 & 0 & 1 & 0.0 \\
post-experience a & 19.173 & 11.689 & 0 & 73 & 7.1 \\
managerial experience & 0.394 & 0.489 & 0 & 1 & 0.0 \\
number of jobs = & 0.275 & 0.446 & 0 & 1 & 0.0 \\
number of jobs $=$ & 0.160 & 0.367 & 0 & 1 & 0.0 \\
\hline search duration before graduation + ? & 1.835 & 4.000 & 0 & 30 & 0.0 \\
search duration after graduation $a+?$ & 2.748 & 4.178 & 0 & 30 & 7.2 \\
\# applications a+? & 8.356 & 12.481 & 0 & 100 & 11.5 \\
\# modes of search a+? & 2.571 & 2.123 & 0 & 13 & 8.7 \\
\# interviews $a$ & 3.573 & 3.738 & 0 & 79 & 11.1 \\
\hline \# job perks $a$ & 0.472 & 1.104 & 0 & 8 & 73.8 \\
abs deviation hours a & 3.834 & 5.075 & 0 & 35 & 3.1 \\
public sector & 0.083 & 0.277 & 0 & 1 & 0.0 \\
educational sector & 0.126 & 0.332 & 0 & 1 & 0.0 \\
private service sector & 0.291 & 0.454 & 0 & 1 & 0.0 \\
health sector & 0.170 & 0.376 & 0 & 1 & 0.0 \\
industrial sector & 0.094 & 0.292 & 0 & 1 & 0.0 \\
full time job & 0.953 & 0.211 & 0 & 1 & 0.0 \\
\hline & & & & &
\end{tabular}

to some extend but we found very similar estimation results as the ones reported in this paper. Since the IV-option is not applicable in the ML-estimation and because estimating a very large simultaneous model is not feasible, we decided to ignore this problem.

If we compare our explanatory variables with other empirical research on reservation wages there are some deviations. Some research uses unemployment insurance benefits (e.g. Kiefer and Neumann (1979) and Hofler and Murphy (1994)) as a measure for alternative income. Kiefer and Neumann (1979) also use the duration of the social benefits. Both variables are not relevant in our case since we are dealing with young people that have just graduated from school. They have no relevant labour market history and therefore can only rely on a very basic social benefit of lifelong duration and equal to $70 \%$ of the minimum 
wage. Non-labour income or wealth, sometimes partly measured by home ownership, is used by Kiefer and Neumann (1979), Hofler and Murphy (1994) and Bloemen and Stancanelli (2001). Unfortunately we do not have full information on this kind of variables. In our opinion this is not a big issue because we investigate the behaviour of very young people who did not yet have the chance to accumulate wealth. A variable that is available and that is related to wealth is study debt. We included logdebt in our reservation wage specification where we also added a dummy for those persons without a study debt. Some of them might already own a house, but we expect that their number will be relatively small and on top of that for almost all of them the house will be burdened by a mortgage. Family income is used as an explanatory variable of the reservation wage by Hofler and Murphy (1994) and Bloemen and Stancanelli (2001). Again we do not have information on this specific variable but we proxy it to some extent by including a dummy for respondents with a partner, dummies for the educational level of the partner, dummies for the partner working part-time or fulltime and interaction effects of these last two dummies with educational level of the partner. We also added dummies indicating whether the individual has a child or is still living with his parents. The unemployment rate is included by Kiefer and Neumann (1979) and Hofler and Murphy (2004). We included time dummies to catch fluctuations in the unemployment rate in time and regional dummies to allow for regional differences in the unemployment rate. Additional to most research on reservation wages we included several indicators of search activity (search duration before and after graduation, the number of applications, the number of modes of search and the number of invitations for interview) and some nonwage job characteristics (number of job perks and the absolute difference between desired and actual working hours).

Only limited empirical research has been done on starting wages. There is no reason to treat starting wages differently from wages in general except for initial uncertainty of the quality of the match (cf. Feng Liang et al (2009) and Berkhout et al (2010)). Unfortunately we do not have information on the quality of the allocation. 


\section{Empirical results}

\subsection{Taking reservation wages at face value}

Due to the high correlation between reservation and starting wage we noted in our data (see below) and because many explanatory variables have an impact on both wages, the estimation of a structural model will be marred by the problem of identification. However, in Table 3 we start with separate OLS regressions and then there is no technical problem. We can therefore include all our variables in the regression for both reservation wage and starting wage. There is of course a problem of interpretation and biased estimation results, but we will use the OLS only for a first reconnaissance. We use the full sample here, so we ignore the problem that for about $30 \%$ of the observations the reservation wage is equal to the starting wage.

We distinguish three groups of variables in the reservation wage: market perceptions (shifts in the wage offer distribution), opportunity cost and the search process. Many results can be interpreted as correct perceptions. Males set a $2 \%$ higher reservation wage than comparable females. For every additional year of age, respondents state a 1\% higher reservation wage. Regional differences are anticipated in the right direction. The south and especially the west of the Netherlands are the more economically developed regions, and individuals set higher reservation wages there. Strong effects are found for the schooling variables. Those respondents that have earned an academic degree demand some $10 \%$ higher wage than those who earned a HBO-degree. Given the Dutch educational system this is no surprise (cf. section 3). Good students have higher reservation wages. For every additional average point-grade ${ }^{11}$ the reservation wage rises with $2.1 \%$. If the number of working hours is deviating from the desired number of working hours a financial compensation of $0.2 \%$ per weekly hour is required. Experience effects in starting wages are well reflected in reservation wages. Internships, managerial experience and relevant experience as a student pay off, other types of experience do not, except experience in a typical student job. The latter effect is the only effect not reflected in the reservation wage. Work experience after graduation has no effect, but this is understandable from the short duration of experience for our labour market

11 In the Netherlands a 10 point scale is used at high school, $\mathrm{HBO}$ and university. It ranges from 1 to 10 , where a grade higher than 5.5 is considered to be sufficient. At HBO and university sufficient final grades for each separate course are required to graduate. At high school an insufficient grade van be compensated by a high sufficient grade to a limited extend. 
entrants. Having done part of a study in another country has no effect whatsoever. Being a member of a student association does, despite its ambiguous definition. Not only elite students, members of real student associations, are included in this definition but also members of study associations. ${ }^{12}$ Sector effects are neatly mirrored in the reservation wage, except for manufacturing. Some results are, perhaps, surprising. Individuals with some disability do not set lower reservation wages, and neither do individuals with an immigrant background. In both cases, they correctly anticipate the structure of starting wages. For jobs with many job perks, reservation wages are not lower, but higher: the number of job perks has a strong and positive effect on the reservation wage. This means that even if the nonwage job characteristics are relatively good, a higher wage is demanded. Apparently good jobs are expected to come with both high wages and good other job characteristics. Progressing quickly to graduation is correctly anticipated to pay off by an extra $1 \%$. Remarkably, being slow to graduate also pays off, but this is not significantly reflected in the reservation wage. The lower wage for full time jobs is also surprising.

The opportunity cost of accepting a job is related to the household situation. We indeed find that the reservation wage is higher if there is a partner but the effect is eradicated if the partner works full-time; apparently, staying at home when the partner works full-time is not attractive. If the respondent has a child a $3 \%$ higher wage is demanded and realised. This might capture a nonlinear age effect, but the inclusion of age squared only marginally changes the estimated effect. If the respondent is still living with his/her parents, the reservation wage is lower, as we expected. Having a study debt, as a partial measure of wealth, does not have any impact on the reservation wage. This can be explained by the Dutch legislation with respect to these debts: they do not have to be repaid directly and only if the debtor earns enough money.

The search process itself is set in anticipation of the market conditions, but experience while searching may lead to adjustment of market perceptions. Search duration, whether before or after graduation, is associated with higher reservation wage. At the individual level, with longitudinal observations, one should anticipate a declining reservation wage (unless searchers find out that market conditions are better than they anticipated). Thus, this result is more likely to reflect heterogeneity: for reasons we cannot control for, these individuals have

12 Student associations are social associations not directly linked to a particular field of study. Members have special characteristics, e.g. a large proportion comes from the higher social classes. A student association is directly related to a field of study. These associations organise events directly related to the study and often organise central buying of study books. 
Table 3: OLS-estimations of the reservation and starting wages.

\begin{tabular}{|c|c|c|c|c|c|c|}
\hline \multirow[b]{2}{*}{ Variables } & \multicolumn{3}{|c|}{ log reservation wage } & \multicolumn{3}{|c|}{ log starting wage } \\
\hline & Estimate & |t-ratio| & & Estimate & |t-ratio| & \\
\hline Constant & 1.9138 & (39.16) & $* *$ & 1.8617 & $(60.57) *$ & $* *$ \\
\hline Male & 0.0203 & $(4.96)$ & $* *$ & 0.0200 & $(4.80) *$ & $* *$ \\
\hline physically disabled & -0.0028 & $(0.46)$ & & -0.0042 & $(0.67)$ & \\
\hline Age & 0.0109 & (10.13) & $* *$ & 0.0101 & $(9.53) *$ & $* *$ \\
\hline non Dutch & 0.0125 & $(1.45)$ & & 0.0146 & $(1.77)$ & \\
\hline education mother $a$ & 0.0042 & (2.39) & $*$ & 0.0045 & $(2.50) *$ & \\
\hline Partner & 0.0234 & $(2.01)$ & $*$ & 0.0224 & $(1.90)$ & \\
\hline partner wo educated & -0.0168 & $(0.75)$ & & -0.0100 & $(0.45)$ & \\
\hline partner hbo educated & -0.0197 & $(0.87)$ & & -0.0149 & $(0.66)$ & \\
\hline partner parttimer & -0.0133 & $(0.94)$ & & -0.0078 & $(0.54)$ & \\
\hline partner fulltimer & -0.0263 & $(2.12)$ & * & -0.0251 & $(1.99) *$ & \\
\hline partner parttimer $\mathrm{x}$ higher educated & 0.0383 & $(1.45)$ & & 0.0298 & $(1.13)$ & \\
\hline partner fulltimer $\mathrm{x}$ higher educated & 0.0373 & $(1.62)$ & & 0.0313 & $(1.36)$ & \\
\hline Child & 0.0332 & $(3.03)$ & $* *$ & 0.0287 & $(2.61) *$ & $* *$ \\
\hline living with parents $a$ & -0.0163 & $(2.81)$ & $* *$ & -0.0159 & $(2.71) *$ & $* *$ \\
\hline north & -0.0220 & $(2.65)$ & $* *$ & -0.0176 & $(2.12) *$ & $*$ \\
\hline West & 0.0226 & $(4.72)$ & $* *$ & 0.0232 & $(4.76) *$ & $* *$ \\
\hline South & 0.0096 & $(1.73)$ & & 0.0088 & $(1.57)$ & \\
\hline logdebt $a$ & -0.0020 & $(1.08)$ & & -0.0019 & $(0.99)$ & \\
\hline no debt a & -0.0026 & $(0.54)$ & & -0.0028 & $(0.56)$ & \\
\hline academic degree & 0.1000 & $(8.68)$ & $* *$ & 0.1083 & $(9.19) *$ & ** \\
\hline average exam grade & 0.0212 & $(6.24)$ & $* *$ & 0.0240 & $(7.00) *$ & ** \\
\hline duration of education short $a$ & 0.0100 & $(2.28)$ & $*$ & 0.0102 & $(2.31) *$ & $*$ \\
\hline duration of education long a & 0.0095 & $(1.76)$ & & 0.0114 & $(2.07) *$ & * \\
\hline studied abroad & 0.0042 & $(1.02)$ & & 0.0063 & $(1.47)$ & \\
\hline membership of a student association & 0.0079 & $(1.78)$ & & 0.0094 & $(2.08) *$ & * \\
\hline
\end{tabular}


Table 3 continued

\begin{tabular}{|c|c|c|c|c|c|c|}
\hline \multirow[b]{2}{*}{ Variables } & \multicolumn{3}{|c|}{ log reservation wage } & \multicolumn{3}{|c|}{ log starting wage } \\
\hline & Estimate & |t-ratio $\mid$ & & Estimate & |t-ratio| & \\
\hline pre-experience in months & 0.0003 & $(0.47)$ & & 0.0003 & $(0.41)$ & \\
\hline not relevant pre-experience & 0.0061 & $(1.58)$ & & 0.0050 & $(1.26)$ & \\
\hline pre-experience due to internship & 0.0161 & (3.95) & $* *$ & 0.0183 & $(4.42)$ & $* *$ \\
\hline pre-experience typical student job & 0.0068 & $(1.86)$ & & 0.0090 & $(2.42)$ & * \\
\hline relevant pre-experience & 0.0303 & $(7.77)$ & $* *$ & 0.0286 & $(7.23)$ & $* *$ \\
\hline post-experience $a$ & 0.0000 & $(0.04)$ & & 0.0000 & $(0.07)$ & \\
\hline managerial experience & 0.0148 & $(3.75)$ & $* *$ & 0.0142 & $(3.56)$ & $* *$ \\
\hline$\#$ jobs $=2$ & 0.0672 & $(9.94)$ & $* *$ & 0.0656 & $(9.49)$ & $* *$ \\
\hline$\#$ jobs $=3$ & 0.0827 & $(10.44)$ & $* *$ & 0.0834 & $(10.33)$ & $* *$ \\
\hline search duration before graduation & 0.0018 & (3.59) & $* *$ & 0.0020 & $(3.92)$ & $* *$ \\
\hline search duration after graduation $a$ & 0.0024 & $(3.45)$ & $* *$ & 0.0027 & (3.83) & $* *$ \\
\hline \# applications a & -0.0010 & $(5.01)$ & $* *$ & -0.0010 & $(5.05)$ & $* *$ \\
\hline \# modes of search a & -0.0092 & $(8.84)$ & $* *$ & -0.0082 & $(7.66)$ & $* *$ \\
\hline$\#$ interviews $a$ & 0.0049 & $(7.49)$ & $* *$ & 0.0047 & $(7.23)$ & $* *$ \\
\hline \# job perks $a$ & 0.0149 & $(6.19)$ & $* *$ & 0.0143 & $(5.90)$ & $* *$ \\
\hline abs deviation hours $a$ & 0.0019 & $(4.76)$ & $* *$ & 0.0016 & $(3.98)$ & $* *$ \\
\hline public sector & 0.0820 & $(11.40)$ & $* *$ & 0.0885 & $(12.06)$ & $* *$ \\
\hline educational sector & 0.0446 & (6.39) & $* *$ & 0.0439 & $(6.27)$ & $* *$ \\
\hline private service sector & 0.0156 & $(3.34)$ & $* *$ & 0.0158 & $(3.28)$ & $* *$ \\
\hline health sector & 0.0801 & (11.11) & $* *$ & 0.0763 & $(10.46)$ & $* *$ \\
\hline manufacturing sector & 0.0512 & $(8.58)$ & $* *$ & 0.0100 & (3.38) & $* *$ \\
\hline \multirow[t]{2}{*}{ full time job } & -0.0434 & $(2.97)$ & $* *$ & -0.0447 & $(3.10)$ & $* *$ \\
\hline & \multicolumn{6}{|c|}{ model parameters } \\
\hline $\mathrm{R}^{2}$ & 0.3127 & & & 0.3110 & & \\
\hline$s^{2}$ & 0.0303 & & & 0.0313 & & \\
\hline \multicolumn{7}{|c|}{$\begin{array}{l}\mathrm{N}=10575 \text { (both equations). } * * *=\text { asymptotically significant at } 5 \% / 1 \% . \alpha=\text { for this variable a dummy for } \\
\text { unknown is added to the specification if the information is missing for the observation (in that case the } \\
\text { variable was put equal to } 0 \text { ). We also added three dummy variables indicating the year the observation was } \\
\text { collected (2006 reference), educational field dummies and employer-size-classes to to both the specification } \\
\text { of the reservation wage and the starting wage. The t-ratios based on robust standard errors are reported. }\end{array}$} \\
\hline
\end{tabular}


set a higher reservation wage and they are prepared to search longer. The number of applications and the number of search modes may also reflect heterogeneity: those who anticipate difficulty finding the job they desire, or who are more risk averse, may search more intensely while at the same time setting a lower reservation wage. But the negative effects we find may also be due to adjustments when market conditions are not as good as anticipated, leading to increases in search intensity and lower reservation wage rate. In particular unsuccessful applications may trigger such adjustment. The number of earlier jobs has strong positive effect: job changers state a 7.0\% (single job change) and 8.5\% (two job changes) higher reservation wage. As such this is a surprising result. Changing jobs once or twice during a very small time period, on average 20 months, is usually not considered to be a good sign. An explanation might be that these respondents apply a stepping-stone strategy. The fact that the estimated effect of multiple job changers is even larger than that of single job changers supports this interpretation. Successful searchers who were invited often to job interviews have a higher reservation wage. Again, this may reflect unobserved heterogeneity or upward adjustment of the reservation wage.

Appendix Table B presents the result of a seemingly unrelated regression. These results should be more efficient, but in fact the differences are negligible. What we gain is an estimate of the correlation between the log net hourly reservation wage and the log net hourly starting wage. At more than $95 \%$, it is very high.

We conclude from the results so far that effects on starting wages are mostly anticipated in the reservation wage and that the effect of opportunity cost on reservation wages indeed tends to translate into a similar effect on realised starting wages. The effects of the search process are not quite what one would predict at the individual level. Indeed, the number of earlier jobs and the number of job interviews ratchet up reservation wage and starting wage. But search duration increases wages and number of applications and number of search modes reduces wages. These effects are more in line with unobserved heterogeneity among individuals than with longitudinal effects for a given individual.

The models explain $26 \%$ and $29 \%$ of the variation in the net hourly reservation and starting wage. The estimated variances of the error terms are very similar in magnitude, but the variance of the actual wage is smaller than we expect. As reported in Table 1, the difference in mean reservation wage and mean starting wage, across the entire sample, is $5.4 \%$. The difference in intercepts in Table 3, reflecting the difference in mean wages if controls had the same effect on reservation wage and starting wage, is $7.3 \%$. Thus, differences 
Table 4: Tobit-estimation of the difference between starting and reservation wages.

\begin{tabular}{|c|c|c|}
\hline \multirow[b]{2}{*}{ Variables } & \multicolumn{2}{|c|}{$\begin{array}{l}\text { log starting wage - } \\
\text { log reservation wage }\end{array}$} \\
\hline & Estimate & |t-ratio \\
\hline Constant & 0.0422 & $(2.53) *$ \\
\hline Male & -0.0006 & $(0.34)$ \\
\hline physically disabled & -0.0029 & $(1.17)$ \\
\hline Age & -0.0011 & $(3.63) * *$ \\
\hline non Dutch & 0.0026 & $(0.79)$ \\
\hline education mother $a$ & 0.0004 & $(0.55)$ \\
\hline Partner & 0.0008 & $(0.17)$ \\
\hline partner wo educated & 0.0078 & $(0.96)$ \\
\hline partner hbo educated & 0.0051 & $(0.62)$ \\
\hline partner parttimer & 0.0071 & $(1.32)$ \\
\hline partner fulltimer & 0.0014 & $(0.29)$ \\
\hline partner parttimer $\mathrm{x}$ higher educated & -0.0107 & $(1.10)$ \\
\hline partner fulltimer $\mathrm{x}$ higher educated & -0.0071 & $(0.84)$ \\
\hline Child & -0.0058 & $(1.49)$ \\
\hline living with parents a & 0.0009 & $(0.37)$ \\
\hline north & 0.0058 & $(1.83)$ \\
\hline West & 0.0010 & $(0.51)$ \\
\hline South & -0.0017 & $(0.73)$ \\
\hline Logdebt $a$ & 0.0002 & $(0.24)$ \\
\hline No debt $a$ & -0.0014 & $(0.68)$ \\
\hline academic degree & 0.0099 & $(1.86)$ \\
\hline Average exam grade & 0.0038 & $(2.72) * *$ \\
\hline Duration of education short $x$ & 0.0008 & $(0.44)$ \\
\hline Duration of education long a & 0.0014 & $(0.64)$ \\
\hline studied abroad & 0.0023 & $(1.33)$ \\
\hline membership of a student association & 0.0026 & $(1.39)$ \\
\hline
\end{tabular}


log starting wage - log reservation wage

\begin{tabular}{|c|c|c|}
\hline Variables & Estimate & |t-ratio| \\
\hline Pre-experience before graduation & -0.0001 & $(0.51)$ \\
\hline not relevant pre-experience & -0.0019 & $(1.16)$ \\
\hline Pre-experience due to internship & 0.0037 & $(2.19) *$ \\
\hline Pre-experience typical student job & 0.0031 & $(1.95)$ \\
\hline relevant pre-experience & -0.0021 & $(1.31)$ \\
\hline post-experience $a$ & 0.0000 & $(0.20)$ \\
\hline managerial experience & -0.0006 & $(0.36)$ \\
\hline number of jobs $=2$ & -0.0010 & $(0.35)$ \\
\hline number of jobs $=3$ & 0.0026 & $(0.81)$ \\
\hline search duration before graduation & 0.0002 & $(1.22)$ \\
\hline search duration after graduation $\alpha$ & 0.0005 & $(1.56)$ \\
\hline \# applications a & -0.0001 & $(1.03)$ \\
\hline \# modes of search $a$ & 0.0013 & $(2.93) * *$ \\
\hline$\#$ interviews $a$ & -0.0001 & $(0.28)$ \\
\hline \# job perks a & -0.0007 & $(0.74)$ \\
\hline abs deviation hours $a$ & -0.0003 & $(1.94)$ \\
\hline public sector & 0.0073 & $(2.44) *$ \\
\hline educational sector & -0.0023 & $(0.80)$ \\
\hline private service sector & 0.0008 & $(0.37)$ \\
\hline health sector & -0.0066 & $(2.30) *$ \\
\hline manufacturing sector & 0.0062 & $(2.17) *$ \\
\hline full time job & -0.0010 & $(0.21)$ \\
\hline $\mathrm{s}^{2}$ & 0.0050 & $(57.07) * *$ \\
\hline \multicolumn{3}{|c|}{$\begin{array}{l}\mathrm{N}=10575 \text { (both equations). } * * *=\text { asymptotically significant at } 5 \% / 1 \% . \quad \alpha=\text { for } \\
\text { this variable a dummy for unknown is added to the specification if the information } \\
\text { is missing for the observation (in that case the variable was put equal to } 0 \text { ). We also } \\
\text { added three dummy variables indicating the year the observation was collected } \\
\text { ( } 2006 \text { reference) to both the specification of the reservation wage and the starting } \\
\text { wage. We also added educational field dummies and employer-size-classes to the } \\
\text { starting wage specification. }\end{array}$} \\
\hline
\end{tabular}


in the effects of the controls increase the gap between reservation wage and starting wage.

Search theory implies that all information on cost and benefits of search is acknowledged in the reservation wage and that the accepted wage is a random hit from the distribution of wage offers. Thus, we expect the gap between reservation wage and accepted starting wage to be a random variable, unrelated to any of our explanatory variables. To test this prediction, we estimate a tobit estimation of the difference between both wages, thus allowing for the fact that in $30 \%$ of our sample the gap is equal to zero. The results are presented in Table 4. The prediction is largely supported. The intercept indicates that on average the difference is about $4.2 \%$. We find only a few systematic effects. The gap is negatively related to age and positively to exam grade, internship experience, number of search modes, and to jobs in the public sector, the health sector and manufacturing. The effects are all very small though: $0.1 \%$ for an additional year of age, $0.4 \%$ for an additional year of internship experience, about $0.5 \%$ for the industrial sectors, less than $0.4 \%$ for an additional grade point average (where grade point average realistically varies between 6 and 9) and 0.1 percent for an additional search mode. Part of this small difference is explained by the $29.3 \%$ of observations for which we observe equal reservation and starting wages. Our next step is to take account of the specific nature of these observations in the way we explained in section 2 .

\subsection{Allowing for selectivity and for doubtful reservation wages}

As noted in section 2, we have some doubts on the reliability of the reservation wage for the large share of the respondents who reported exact equality between reservation wage and accepted starting wage. Nothing in the theory rules out such equality, but if this happens in $30 \%$ of the sample, one may doubt if these respondents really reported their true reservation wage. Model (6) - (8) therefore sets apart those observations where reservation wage and starting wage are exactly identical, and in those cases drops the reported reservation wage.

Table 5 presents the ML-estimation results. For the probit part, the indicator has value 0 for observations with equal reservation and starting wages. Thus, a positive sign indicates stronger inclination to report a reservation wage not equal to starting wage, and suggests a more honest answer. The estimation results indicate that indeed the choice to report equal reservation and starting wages is no coincidence. Men and the academically educated are less likely to do so, as are younger respondents. We also tried other variables characterizing the 
individual but we did not find any other significant effects. ${ }^{13}$ The estimated correlations also indicate that the decision to report equal wages is not random. Both the error term of the reservation wage and the starting wage equation positively correlate with the error term of the probit equation. This indicates that relatively high reservation and starting wage will lead to reporting a difference between them. Allowing for deliberately reporting equal reservation and starting wages does not change the correlation between the error terms of the wage equations in comparison to the earlier SUR result.

With respect to the parameter estimates, we find very similar results to the SURestimation. The standard errors mostly increase somewhat leading to fewer conventionally significant effects. The only difference of any substance is a positive effect of deviating hours on starting wages that earlier was negative (with SUR, not with OLS). We now estimate the difference between average reservation wage and average starting wage if controls had identical effect upon both wages at 7.5\% (from the difference in intercepts).

Since the parameter estimates of reservation and starting wages are quite similar and to test whether the reservation wage is a more or less fixed proportion to the starting wage, the test suggested at the end of section 2 was carried out. We added $\log \left(\mathrm{w}^{\mathrm{s}}\right)$ as an explanatory variable to the reservation wage specification. If the estimated coefficient of this additional variable equals 1 and if, apart from the constant, no other explanatory variables is relevant, then we can conclude that indeed the reservation wage is merely a proportion of the starting wage indicating that respondents have a hard time to identify the reservation wage. The parameter estimate of $\log \left(\mathrm{w}^{\mathrm{s}}\right)$ is 0.953 with a standard error of 0.012 and therefore this estimate differs significantly from 1 . On top of that a large number of explanatory variables are significantly different from zero. ${ }^{14}$

All in all we have to conclude that reservation wages and starting wages do not stand in fixed proportion, but that there is a close relation. Apparently, individuals know the labour market well. They know what characteristics pay off and consequently they know what level of wages to expect. They adapt their reservation wage to this level resulting in parameters estimates that are very similar.

13 We also added $\log \left(w^{s}\right)$ to the probit-part of the model. The resulting parameter estimate is not significantly different from 0 .

14 To be precise: male, age, north, \# applications, \# modes of search, \# interviews, \# job perks, north, , abs deviation hours, number of jobs $=2$ and number of jobs $=3$ are all significant at at least $5 \%$. 
Table 5: ML estimation of the full model

\begin{tabular}{|c|c|c|c|c|c|c|}
\hline \multirow[b]{2}{*}{ Variables } & \multicolumn{3}{|c|}{ probit $w_{i}^{r}<w_{i}^{s}$} & & & \\
\hline & Estimate & $\mid$ t-ratio $\mid$ & & & & \\
\hline constant & 0.5460 & $(5.42)$ & $* *$ & & & \\
\hline male & 0.0700 & $(2.63)$ & $* *$ & & & \\
\hline age & -0.0218 & $(6.00)$ & $* *$ & & & \\
\hline \multirow[t]{2}{*}{ academic education } & 0.2248 & $(8.38)$ & $* *$ & & & \\
\hline & \multicolumn{3}{|c|}{ log reservation wage } & \multicolumn{3}{|c|}{ log starting wage } \\
\hline Variables & Estimate & |t-ratio| & & Estimate & |t-ratio| & \\
\hline constant & 1.6487 & (32.53) & $* *$ & 1.7244 & $(33.89) *$ & $* *$ \\
\hline male & 0.0283 & $(5.27)$ & $* *$ & 0.0283 & $(5.27) *$ & $* *$ \\
\hline physically disabled & -0.0013 & $(0.18)$ & & -0.0001 & $(0.02)$ & \\
\hline age & 0.0103 & $(12.32)$ & $* *$ & 0.0097 & $(11.82) *$ & $* *$ \\
\hline non Dutch & -0.0031 & $(1.05)$ & & -0.0012 & $(0.33)$ & \\
\hline education mother $a$ & 0.0028 & $(1.26)$ & & 0.0028 & $(1.24)$ & \\
\hline partner & 0.0213 & $(1.56)$ & & 0.0192 & (1.39) & \\
\hline partner wo educated & -0.0129 & $(0.53)$ & & -0.0045 & $(0.18)$ & \\
\hline partner hbo educated & -0.0088 & $(0.36)$ & & -0.0013 & $(0.05)$ & \\
\hline partner parttimer & -0.0179 & $(1.10)$ & & -0.0134 & $(0.82)$ & \\
\hline partner fulltimer & -0.0306 & $(2.11)$ & $*$ & -0.0295 & $(2.02) *$ & \\
\hline partner parttimer $\mathrm{x}$ higher educated & 0.0390 & $(1.35)$ & & 0.0306 & $(1.05)$ & \\
\hline partner fulltimer $\mathrm{x}$ higher educated & 0.0382 & $(1.50)$ & & 0.0317 & $(1.24)$ & \\
\hline child & 0.0394 & $(3.58)$ & $* *$ & 0.0355 & $(3.23) *$ & $* *$ \\
\hline living with parents a & -0.0173 & $(2.28)$ & $*$ & -0.0178 & $(2.33) *$ & $*$ \\
\hline north & -0.0238 & $(2.51)$ & $*$ & -0.0195 & $(2.04) *$ & * \\
\hline west & 0.0210 & $(3.46)$ & $* *$ & 0.0208 & $(3.42) *$ & $* *$ \\
\hline south & 0.0182 & $(2.59)$ & $* *$ & 0.0197 & $(2.79) *$ & $* *$ \\
\hline logdebt $a$ & -0.0007 & $(0.32)$ & & -0.0006 & $(0.26)$ & \\
\hline no debt $a$ & 0.0096 & $(1.53)$ & & 0.0127 & $(1.99) *$ & $*$ \\
\hline academic degree & 0.1208 & $(7.26)$ & $* *$ & 0.1285 & $(7.66) *$ & $* *$ \\
\hline average exam grade & 0.0172 & $(4.06)$ & $* *$ & 0.0190 & $(4.45) *$ & $* *$ \\
\hline duration of education short $a$ & 0.0036 & $(0.63)$ & & 0.0026 & $(0.46)$ & \\
\hline duration of education long $a$ & 0.0142 & $(2.06)$ & & 0.0190 & $(2.74) *$ & \\
\hline studied abroad & 0.0025 & $(0.47)$ & & 0.0050 & $(0.90)$ & \\
\hline membership of a student association & -0.0007 & $(0.12)$ & & -0.0015 & $(0.25)$ & \\
\hline
\end{tabular}


Table 5 continued

\begin{tabular}{|c|c|c|c|c|c|c|}
\hline \multirow[b]{2}{*}{ Variables } & \multicolumn{3}{|c|}{ log reservation wage } & \multicolumn{3}{|c|}{ log starting wage } \\
\hline & Estimate & |t-ratio| & & Estimate & |t-ratio| & \\
\hline pre-experience in months & 0.0000 & $(0.00)$ & & 0.0000 & $(0.05)$ & \\
\hline not relevant pre-experience & 0.0108 & $(2.14)$ & $*$ & 0.0109 & $(2.14)$ & $*$ \\
\hline pre-experience due to internship & 0.0045 & $(0.87)$ & & 0.0040 & $(0.77)$ & \\
\hline pre-experience typical student job & 0.0051 & $(1.08)$ & & 0.0064 & $(1.32)$ & \\
\hline relevant pre-experience & 0.0307 & $(6.25)$ & $* *$ & 0.0292 & $(5.89)$ & $* *$ \\
\hline post-experience $a$ & 0.0001 & $(0.08)$ & & 0.0001 & $(0.12)$ & \\
\hline managerial experience & 0.0156 & $(3.12)$ & $* *$ & 0.0148 & $(2.95)$ & $* *$ \\
\hline number of jobs = 2 & 0.0591 & $(6.67)$ & $* *$ & 0.0553 & $(6.19)^{\prime}$ & $* *$ \\
\hline number of jobs $=3$ & 0.0644 & $(6.51)$ & $* *$ & 0.0613 & $(6.14)^{\prime}$ & $* *$ \\
\hline search duration before graduationø & 0.0014 & $(2.48)$ & * & 0.0015 & $(2.66)$ & $* *$ \\
\hline search duration after graduation $a$ & 0.0010 & $(1.14)$ & & 0.0011 & $(1.19)$ & \\
\hline \# applications a & -0.0008 & $(3.42)$ & $* *$ & -0.0007 & $(3.01)$ & $* *$ \\
\hline \# modes of search $a$ & -0.0117 & $(8.52)$ & $* *$ & -0.0112 & $(8.08)$ & $* *$ \\
\hline \# interviews $a$ & 0.0039 & $(5.00)$ & $* *$ & 0.0034 & $(4.36)$ & $* *$ \\
\hline \# job perks a & 0.0121 & $(4.02)$ & $* *$ & 0.0111 & $(3.65)^{\prime}$ & $* *$ \\
\hline abs deviation hours $x$ & 0.0017 & $(3.67)$ & $* *$ & 0.0013 & $(2.78)$ & $* *$ \\
\hline public sector & 0.0933 & $(10.05)$ & $* *$ & 0.1016 & $(10.83)$ & $* *$ \\
\hline educational sector & 0.0660 & $(7.71)$ & $* *$ & 0.0708 & $(8.22)$ & $* *$ \\
\hline private service sector & 0.0119 & $(1.83)$ & & 0.0110 & $(1.67)$ & \\
\hline health sector & 0.1039 & $(12.22)$ & $* *$ & 0.1063 & $(12.44)$ & $* *$ \\
\hline industrial sector & 0.0503 & $(5.56)$ & $* *$ & 0.0539 & $(5.89)$ & $* *$ \\
\hline \multirow[t]{3}{*}{ full time job } & -0.0390 & $(3.13)$ & $* *$ & -0.0408 & $(3.26)$ & $* *$ \\
\hline & \multicolumn{6}{|c|}{ model parameters } \\
\hline & \multicolumn{3}{|c|}{ Estimate } & |t-ratio| & & \\
\hline variance error reservation wage $\left(\sigma_{\mathrm{r}}^{2}\right)$ & \multicolumn{3}{|c|}{0.0279} & $(65.70) * x$ & & \\
\hline variance error starting wage $\left(\sigma_{\mathrm{s}}{ }^{2}\right)$ & \multicolumn{6}{|c|}{$0.0267 \quad(67.50)$} \\
\hline correlation between $\varepsilon_{\mathrm{ri}}$ and $\varepsilon_{\mathrm{si}}$ & \multicolumn{6}{|c|}{$0.9546(872.73) * *$} \\
\hline correlation between $\varepsilon_{\mathrm{ri}}$ and $\zeta_{\mathrm{i}}$ & \multicolumn{6}{|c|}{$0.3472(27.87) * *$} \\
\hline correlation between $\varepsilon_{\mathrm{si}}$ and $\zeta_{\mathrm{i}}$ & \multicolumn{3}{|c|}{0.2364} & $(21.06) * *$ & & \\
\hline
\end{tabular}

$\mathrm{N}=10575 . * * *=$ asymptotically significant at $5 \% / 1 \%$. $\mathrm{o}=$ for this variable a dummy for unknown is added to the specification if the information is missing for the observation (in that case the variable was put equal to 0 ). We also added three dummy variables indicating the year the observation was collected (2006 reference) to both the specification of the reservation wage and the starting wage. We also added educational field dummies and employer-size-classes to the starting wage specification. 


\section{Conclusion}

In this paper we have investigated the relation between reservation and starting wages. Theory predicts that all market information is included in the reservation wage and that the gap between accepted starting wage for a job and the reservation wage for that type of job is a random variable, not systematically related to personal or job characteristics. Basically, both predictions are supported in our data. Variables that significantly affect the starting wage also significantly affect the reservation wage, at the same magnitude. Having a partner that works full time and living with parents reduce reservation and market wage, having a child raises both. Other variables that reflect differences in opportunity cost of accepting a job are insignificant. We find slightly more significant effects if we estimate the reservation wage equation with OLS. This difference is in line with the difference between conditional and unconditional starting wages. The latter should reflect the distribution of wage offers, which should not be sensitive to opportunity cost of individuals. The former just considers the effect on accepted wages, which will be pushed up by higher reservation wage if opportunity cost is higher. But the differences are modest, and do not reflect a clear systematic effect.

Perhaps the key weakness of our data is the timing of response on the reservation wage question. The question is asked of employees for the job they presently hold. Hence, anchoring answers to actual wage may seriously distort the accuracy of the measurement. We find indeed that $30 \%$ of the respondents equate reservation wage and actual wage. To counter this distortion, we acknowledge it in our econometric model. Also, we checked the relationship between reservation wage and actual wage and clearly reject fixed proportionality. Thus we believe that the variation in the difference between reservation wage and actual wage generates meaningful information and that our results have sufficient credibility to take them serious and to build on them in further research. 


\section{Refererences}

Berg, G. van den, and G. Ridder, 1998, An empirical equilibrium search model of the labor market, Econometrica, vol. 66, pp. 1183-1221.

Berkhout, P., J. Hartog and H. van Ophem, 2010, Starting wages respond to employer's risk, working paper, Faculty of Economics and Business, University of Amsterdam.

Blackalby, D.H., P.L. Latreille, P.D. Murphy, N.C. O'Leary and P.J. Sloane, 2007, An analysis of reservation wages for the economically inactive, Economics Letters, vol. 97, pp. 15.

Benhabib, J. and C. Bull, 1983, Job search: the choice of intensity, Journal of Political Economy, vol. 91, pp. 747-764.

Blau, D.M. and Ph. K. Robins, 1990, Job search outcomes for the employed and unemployed, Journal of Political Economy, vol. 98, pp. 637-655.

Bloemen, H.G., and E.G.F. Stancanelli, 2001, Individual wealth, reservation wages, and transitions into employment, Journal of Labor Economics, vol. 19, pp. 400-439.

Bloemen, H.G., 2005, Job search, search intensity, and labor market transition: an empirical analysis, Journal of Human Resources, vol. 40, pp. 231-269.

Bowlus, A., N.M. Kiefer and G.R. Neumann, Equilibrium search models and the transition form school to work, International Economic Review, vol. 42, pp. 317-343.

Burdett, K., 1978, Employee search and quits, The American Economic Review, vol. 68, pp. 212-220.

Burdett, K., and T. Vishwanath, 1988, Declining reservation wages and learning, The Review of Economic Studies, vol. 55, pp. 655-665.

Eckstein, Z., and G.J. van den Berg, 2006, Empirical labor search: a survey, Journal of Econometrics, vol. 136, pp. 531-564.

Eckstein, Z., and K.I. Wolpin, 1995, Duration to first job and the return to schooling: estimates from a search-matching model, The Reviews of Economic Studies, vol. 62, pp. 263-286.

Eckstein, Z., and K.I. Wolpin, 1999, Estimating the effect of racial discrimination on first job wage offers, The Review of Economics and Statistics, vol. 81, pp. 384-392.

FengLiang, L., D. Xiaohao and W.J. Morgan, 2009, Higher education and the starting wages of graduates in China, International Journal of Educational Development, vol. 29, pp. 374-381. 
Gørgens, T., 2002, Reservation wages and working hours for recently unemployed US women, Labour Economics, vol. 9, pp. 93-123.

Hofler, R.A. and K.J. Murphy, 1994, Estimating reservation wages of employed workers using a stochastic frontier, Southern Economic Journal, vol. 60, pp. 961-976.

Jones, S.R.G., 1988, The relationship between unemployment spells and reservation wages as a test of search theory, The Quarterly Journal of Economics, vol. 103., pp. 741-765.

Kasper, H., 1967, The asking price of labor and the duration of unemployment, The Review of Economics and Statistics, vol. 49, pp. 165-172.

Kiefer, N.M. and G.R. Neumann, 1979, An empirical job-search model with a test of the constant reservation-wage hypothesis, Journal of Political Economy, vol. 87, pp. 89107.

Klaauw, B. van der, and A. van Vuuren, 2010, Job search and academic achievement, European Economic Review, vol. 54, pp. 294-316.

Lancaster, T., and A. Chesher, 1983, An econometric analysis of reservation wages, Econometrica, vol. 51, pp. 1661-1676.

Lippman, S.A., and J.J. McCall, 1976, The economics of job search: a survey, Economic Inquiry, vol. 14, pp.155-189.

Kiefer, N.M., and G.R. Neumann, 1979, An empirical job-search model with a test of the constant reservation-wage hypothesis, Journal of Political Economy, vol. 87, pp. 89107.

Orazem, P.F., J.D. Werbel and J.C. McElroy, 2003, Market expectations, job search, and gender differences in starting pay, Journal of Labor Research, vol. XXIV, pp.307-321.

Pissarides, Ch., 1984, Search intensity, job advertising, and efficiency, Journal of Labor Economics, vol. 2, pp. 128-143.

Webb, R., D. Watson and T. Hinks, 2003, Testing for wage overpayment in UK financial services: a stochastic frontier approach, The Service Industries Journal, vol. 23, pp. 123-136.

Watson, D. and R. Webb, 2008, Reservation wage levels in UK and German financial services sectors, The Service Industries Journal, vol. 28, pp. 1167-1182.

Wolpin, K.I., 1987, Estimating a structural search model: the transition from school to work, Econometrica, vol. 55, pp. 801-817. 


\section{Appendix A. Definition of variables}

Individual characteristics:

- male: dummy variable equal to 1 for male respondents;

- physically disabled; dummy variable equal to 1 if the respondent reports to be physically disabled;

- age: the age of the respondent;

- non Dutch: dummy variable equal to 1 if the respondent states to have a non-Dutch background;

- education mother: educational level of the mother of the respondent;

- partner: dummy variable equal to 1 if the respondent is living together with another person (not a child);

- partner wo educated: dummy variable equal to 1 if the partner of the respondent has completed a university education;

- partner hbo educated: dummy variable equal to 1 if the partner of the respondent has completed higher vocational education;

- partner parttimer: dummy variable equal to 1 if the partner of the respondent works, but less than 32 hours per week

- partner fulltimer: dummy variable equal to 1 if the partner of the respondent works at least 32 hours per week

- partner parttimer x higher educated: partner parttimer times (partner wo educated + partner hbo educated)

- partner fulltimer x higher educated: partner fulltimer times (partner wo educated + partner hbo educated)

- child: dummy variable equal to 1 if the respondent has a child;

- living with parents: dummy variable equal to 1 if the respondents is still living with his/her parents;

- north: dummy variable equal to 1 if the respondent is living in the northern part of the Netherlands;

- west: dummy variable equal to 1 if the respondent is living in the western part of the Netherlands;

- south: dummy variable equal to 1 if the respondent is living in the southern part of the Netherlands; 
- logdebt: the logarithm of the study debt. Put to 0 if the respondent does not have a study debt;

- no debt: dummy variable equal to 1 if the respondent does not have a debt due to his/her studies.

Characteristics of the education completed:

- academic degree: dummy variable equal to 1 if the respondent has completed a university education (reference: respondent completed higher vocational education);

- average exam grade: the average of the grades earned in university or higher vocational education as reported by the respondent. Grading uses a standard 0-10 scale; passing requires a minimum of 5.5, though not necessarily for all courses, as compensation is sometimes allowed;

- duration of education short: dummy variable equal to 1 if the actual duration of university or higher vocational education is shorter than the nominal duration (usually 4 years);

- duration of education long: dummy variable equal to 1 if the actual duration of university or higher vocational education is longer than 6 years (nominal duration usually 4 years);

- studied abroad: dummy variable equal to 1 if the respondent took some of his/her education abroad;

- membership of a student association: dummy variable equal to 1 if the respondent was a member of a student association during his/her studies;

Variables relating to labour market experience:

- pre-experience: total of the work experience of the respondent in months before the first job after graduation was accepted;

- not relevant pre-experience : the work experience of the respondent in months before the first job was accepted that is not relevant for this first job (relevance assessed by respondent);

- pre-experience due to internship: the work experience of the respondent in months before the first job was accepted due to internships;

- pre-experience typical student job: the work experience of the respondent in months 
before the first job was accepted gained in a typical student job;

- relevant pre-experience: the relevant work experience of the respondent in months before the first job was accepted (relevance assessed by respondent);

- post-experience: the labour market experience of the respondent in months until starting with the present job;

- managerial experience: dummy variable equal to 1 if the respondent claims to have gained some managerial experience during his/her working life;

- number of jobs $=2$ : dummy variable equal to 1 if the respondent has had 2 different jobs in the period between graduation and the moment the questionnaire was completed ;

- number of jobs = 3: dummy variable equal to 1 if the respondent has had 3 different jobs in the period between graduation and the moment the questionnaire was completed.

Job search characteristics:

- search duration before graduation: job search duration in months before the study was completed;

- search duration after graduation: job search duration until acceptance of first job, in months after graduation;

- \# applications: the total number of job applications of the respondent before the first job was accepted;

- \# modes of search: the total number of different modes of search used to find a first job (e.g. reading newspapers and magazines with personnel advertisements, open applications, employment agencies etc.);

- \# interviews: the total number of times the respondent was invited for a job interview before he/she accepted the first job.

Present job characteristics:

- \# job perks: the number of nonwage characteristics of the first job (e.g. child care provided by employer, a bonus in stocks or money, computer, car or mobile phone provided by the employer etc.);

- abs deviation hours: the absolute difference between the desired number and actual 
number of working hours;

- public sector: dummy variable equal to 1 if the first job was in the public sector;

- educational sector: dummy variable equal to 1 if the first job was in the educational sector;

- private service sector: dummy variable equal to 1 if the first job was in the private service sector;

- health sector: dummy variable equal to 1 if the first job was in the health sector;

- industrial sector: dummy variable equal to 1 if the first job was in the industrial sector;

- full time job: dummy variable equal to 1 if the first job was a full time job. 
Appendix B: Table A1: SUR-estimation of the reservation and starting wages.

\begin{tabular}{|c|c|c|c|c|c|c|}
\hline \multirow[b]{2}{*}{ Variables } & \multicolumn{3}{|c|}{ log reservation wage } & \multicolumn{3}{|c|}{ log starting wage } \\
\hline & Estimate & $\mid$ t-ratio $\mid$ & & Estimate & |t-ratio| & \\
\hline Constant & 1.9138 & $(49.05)$ & $* *$ & 1.9684 & (49.64) & $* *$ \\
\hline Male & 0.0203 & $(5.01)$ & $* *$ & 0.0200 & $(4.85)$ & $* *$ \\
\hline physically disabled & -0.0028 & $(0.48)$ & & -0.0042 & $(0.70)$ & \\
\hline Age & 0.0109 & (15.83) & $* *$ & 0.0101 & $(14.47)$ & $* *$ \\
\hline non Dutch & 0.0125 & $(1.61)$ & & 0.0146 & $(1.84)$ & \\
\hline education mother $a$ & 0.0042 & $(2.41)$ & * & 0.0045 & $(2.52)$ & $*$ \\
\hline Partner & 0.0234 & (2.19) & $*$ & 0.0224 & $(2.07)$ & $*$ \\
\hline partner wo educated & -0.0168 & $(0.87)$ & & -0.0100 & $(0.51)$ & \\
\hline partner hbo educated & -0.0197 & $(1.01)$ & & -0.0149 & $(0.75)$ & \\
\hline partner parttimer & -0.0133 & $(1.04)$ & & -0.0078 & $(0.60)$ & \\
\hline partner fulltimer & -0.0263 & $(2.32)$ & * & -0.0251 & $(2.18)$ & $*$ \\
\hline partner parttimer $\mathrm{x}$ higher educated & 0.0383 & $(1.67)$ & & 0.0298 & $(1.28)$ & \\
\hline partner fulltimer $\mathrm{x}$ higher educated & 0.0373 & $(1.85)$ & & 0.0313 & $(1.53)$ & \\
\hline Child & 0.0332 & (3.67) & $* *$ & 0.0287 & $(3.13)$ & $* *$ \\
\hline living with parents $a$ & -0.0163 & $(2.76)$ & $* *$ & -0.0159 & $(2.65)$ & $* *$ \\
\hline north & -0.0221 & $(2.95)$ & $* *$ & -0.0176 & $(2.32)$ & $*$ \\
\hline West & 0.0226 & $(4.79)$ & $* *$ & 0.0232 & $(4.83)$ & $* *$ \\
\hline South & 0.0096 & (1.73) & & 0.0088 & (1.56) & \\
\hline logdebt $a$ & -0.0020 & $(1.10)$ & & -0.0019 & $(1.02)$ & \\
\hline no debt $a$ & -0.0026 & $(0.54)$ & & -0.0028 & $(0.57)$ & \\
\hline academic degree & 0.1000 & $(7.91)$ & $* *$ & 0.1083 & $(8.42)$ & $* *$ \\
\hline average exam grade & 0.0212 & $(6.40)$ & $* *$ & 0.0240 & $(7.12)$ & $* *$ \\
\hline duration of education short a & 0.0100 & $(2.27)$ & $*$ & 0.0102 & (2.29) & $*$ \\
\hline duration of education long a & 0.0095 & $(1.78)$ & & 0.0114 & $(2.11)$ & $*$ \\
\hline studied abroad & 0.0042 & $(1.01)$ & & 0.0063 & $(1.47)$ & \\
\hline membership of a student association & 0.0079 & $(1.77)$ & & 0.0094 & $(2.06)$ & $*$ \\
\hline
\end{tabular}


Appendix Table B continued

\begin{tabular}{|c|c|c|c|c|c|c|}
\hline \multirow[b]{2}{*}{ Variables } & \multicolumn{3}{|c|}{ Log reservation wage } & \multicolumn{3}{|c|}{ log starting wage } \\
\hline & Estimate & |t-ratio & & Estimate & |t-ratio| & \\
\hline pre-experience & 0.0003 & $(0.50)$ & & 0.0003 & $(0.43)$ & \\
\hline not relevant pre-experience & 0.0061 & $(1.56)$ & & 0.0049 & $(1.24)$ & \\
\hline pre-experience due to internship & 0.0161 & $(4.02)$ & $* *$ & 0.0183 & $(4.48)$ & $* *$ \\
\hline pre-experience typical student job & 0.0068 & $(1.84)$ & & 0.0090 & $(2.38)$ & * \\
\hline relevant pre-experience & 0.0303 & $(7.89)=$ & $* *$ & 0.0286 & $(7.33)$ & $* *$ \\
\hline post-experience a & 0.0000 & $(0.05)$ & & 0.0000 & $(0.07)$ & \\
\hline managerial experience & 0.0148 & $(3.81)^{\prime}$ & $* *$ & 0.0142 & $(3.61)$ & $* *$ \\
\hline$\#$ jobs $=2$ & 0.0672 & $(9.78)$ & $* *$ & 0.0656 & $(9.39)$ & $* *$ \\
\hline$\#$ jobs $=3$ & 0.0827 & $(10.77)$ & $* *$ & 0.0834 & $(10.68)$ & $* *$ \\
\hline search duration before graduation & 0.0018 & $(3.98)$ & $* *$ & 0.0020 & $(4.30)$ & $* *$ \\
\hline search duration after graduation $\propto$ & 0.0024 & $(3.49)$ & $* *$ & 0.0027 & $(3.85)$ & $* *$ \\
\hline \# applications a & -0.0010 & $(5.43)$ & $* *$ & -0.0010 & $(5.51)$ & $* *$ \\
\hline \# modes of search $a$ & -0.0092 & $(8.82)$ & $* *$ & -0.0082 & $(7.77)$ & $* *$ \\
\hline \# interviews $a$ & 0.0049 & $(8.33)$ & $* *$ & 0.0047 & $(7.95)$ & $* *$ \\
\hline \# job perks a & 0.0149 & $(6.58)$ & $* *$ & 0.0143 & $(6.21)$ & $* *$ \\
\hline abs deviation hours $a$ & 0.0019 & $(5.12)$ & $* *$ & -0.0016 & $(4.31)$ & $* *$ \\
\hline public sector & 0.0820 & $(11.55)$ & $* *$ & 0.0885 & $(12.27)$ & $* *$ \\
\hline educational sector & 0.0446 & $(6.57)$ & $* *$ & 0.0439 & (6.38) & $* *$ \\
\hline private service sector & 0.0156 & $(3.17)$ & $* *$ & 0.0158 & (3.15) & $* *$ \\
\hline health sector & 0.0801 & $(11.90)$ & $* *$ & 0.0763 & (11.17) & $* *$ \\
\hline industrial sector & 0.0512 & $(7.58)$ & $* *$ & 0.0558 & $(8.14)$ & $* *$ \\
\hline \multirow[t]{2}{*}{ full time job } & -0.0434 & $(4.21)^{\prime}$ & $* *$ & -0.0447 & $(4.26)$ & $* *$ \\
\hline & \multicolumn{6}{|c|}{ model parameters } \\
\hline $\mathrm{R}^{2}$ & \multicolumn{3}{|l|}{0.3127} & \multicolumn{3}{|l|}{0.3110} \\
\hline $\mathrm{s}^{2}$ & \multicolumn{3}{|l|}{0.0300} & \multicolumn{2}{|l|}{0.0310} & \\
\hline correlation between $\varepsilon_{\mathrm{ri}}$ and $\varepsilon_{\mathrm{si}}$ & \multicolumn{6}{|c|}{$0.9537 \dagger$} \\
\hline \multicolumn{7}{|c|}{$\begin{array}{l}\mathrm{N}=10575 . * / *=\text { asymptotically significant at } 5 \% / 1 \% \text {. } \mathrm{a}=\text { for this variable a dummy for unknown is added to the } \\
\text { specification if the information is missing for the observation (in that case the variable was put equal to } 0 \text { ). We also } \\
\text { added three dummy variables indicating the year the observation was collected ( } 2006 \text { reference), educational field } \\
\text { dummies and employer-size-classes to to both the specification of the reservation wage and the starting wage.The t- } \\
\text { ratios based on robust standard errors are reported. } \dagger=\text { significant at } 1 \% \text { (Breusch-Pagan test-statistic on } \\
\text { independence }=9618 \text {, chi-square(1) distributed). }\end{array}$} \\
\hline
\end{tabular}

